\title{
Flush Air Data Sensing for Soaring-Capable UAVs
}

\author{
John. F. Quindlen* \\ Jack W. Langelaan ${ }^{\dagger}$ \\ The Pennsylvania State University, University Park, PA 16802, USA
}

\begin{abstract}
Dynamic soaring extracts energy from naturally occurring wind gradients that can be used to extend aircraft endurance, particularly in small UAVs. Autonomous thermal soaring has already been validated in flight tests with small UAVs, but this level of demonstration has not been performed for dynamic soaring UAVs, partly due to the precise wind measurements required. This paper explores wind vector sensing using flush pressure ports located on the nose of small sailplanes. Single Hidden Layer neural networks are used to generate regression models to calculate the airspeed, angle of attack, and angle of sideslip and are trained with pressure measurements collected during wind tunnel tests. These models are then applied to pressure measurements taken during flight tests of the aircraft and sensing system to judge the viability of the method.
\end{abstract}

\section{Introduction}

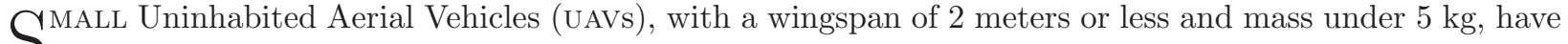
$S$ tremendous potential in military and civilian applications. These aircraft are usually hand-launchable with small operational footprints, but this small size also limits payload capacity and flight endurance. Endurance can be added by means of extra batteries or fuel, but at the expense of mission equipment. Autonomous soaring techniques offer the ability to increase aircraft endurance without sacrificing mission payload. These soaring techniques are directly inspired by birds, which use several different approaches toward extracting energy from the environment.

Static soaring is the most common and widely known technique utilizing upwards moving sources of air to gain altitude. Birds and sailplane pilots already rely upon thermal soaring in regions of rising warm air to remain aloft for indefinite periods of time. In addition to thermals, rising air on the windward side of ridges can be used as a source of lift as can certain regions downwind of tall mountains. Work has already demonstrated the ability of small UAVs to extend endurance using static soaring techniques, mainly with thermals. Allen and Lin [1] investigated thermal identification with the Cloud Swift UAV and successfully extracted energy from thermals, even weak ones. Andersson et al. [2,3] have also flight tested thermal soaring with small UAVs using energy estimation for control. Edwards and Silverberg [4,5] have even demonstrated that UAVs can beat human controlled aircraft in cross country flight competitions using these autonomous soaring techniques. These results show that autonomous soaring offers a viable means of extending endurance on small UAVs.

In addition to thermal soaring, dynamic soaring exploits naturally-occurring wind shear gradients. Dynamic soaring takes advantage of the spatial wind gradients occurring either at the surface or at altitude using carefully controlled climbs into the wind and dives with the tailwind to gain or maintain energy. This phenomena was first described by Lord Rayleigh [6] and has been widely described in albatrosses and petrels by Pennyquick [7]. Gordon [8] demonstrated the feasibility of dynamic soaring in manned gliders, although flight test performance was limited due to safety and airframe limitations. Sachs et al. [9] have recorded albatross flights of hundreds of kilometers accomplished using dynamic soaring maneuvers. While many birds are seen thermal soaring, only certain species of albatrosses and petrels are observed dynamic soaring [10]. Pennyquick [7] proposed that petrels and albatrosses are capable of dynamic soaring flight due to the presence of specialized sensory organs that function similar to pitot tubes. Shown in Figure 1,

\footnotetext{
* currently graduate student at the Massachusetts Institute of Technology, Student Member AIAA.

$\dagger$ Associate Professor, Department of Aerospace Engineering, Associate Fellow AIAA.
} 
small tubular nostrils on the beak measure total pressure while sensory glands in the mouth measure static pressure. The larger Diomedeidae birds have two nostrils on either side of the beak that also can function for yaw detection. These adaptations are only seen in birds that regularly utilize dynamic soaring for long duration flights and are what enable them to fly the precise maneuvers required. In order for small aircraft to harvest energy in this manner, they need the same sensing capabilities as petrels and albatrosses.

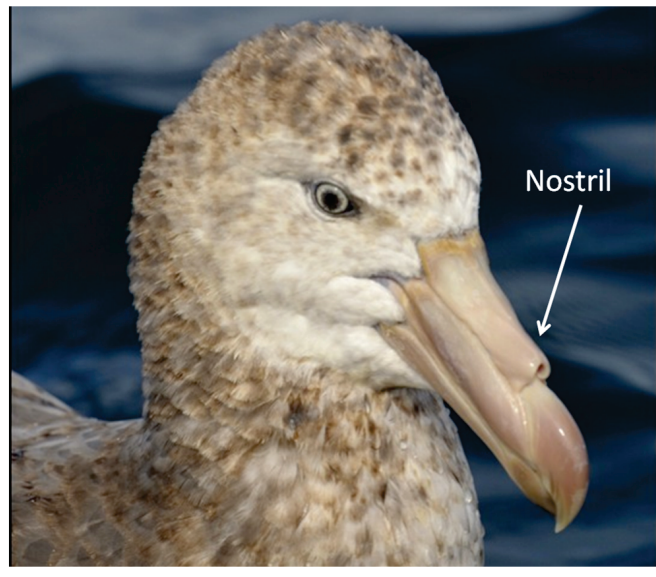

(a) Giant Petrel

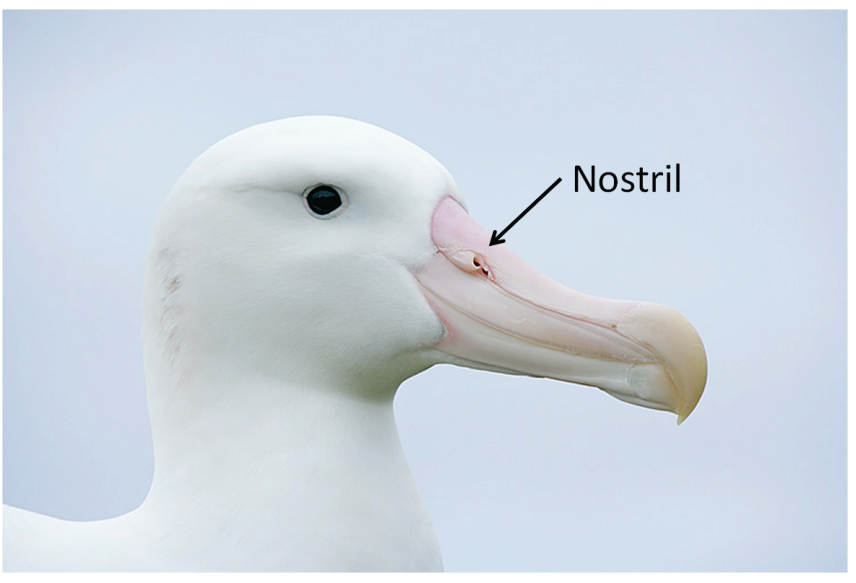

(b) Wandering Albatross

Figure 1. Procellariiform nostrils.

A variety of methods can be used for wind vector sensing on aircraft. Typical air data sensing systems consist of pressure ports or probes to measure dynamic and static pressure. Vanes may also be used to measure angle of attack and angle of sideslip. These techniques have been successfully used on manned aircraft or comparatively sized UAVs [11]; however, these are typically expensive when compared to the cost of small UAVs and will result in weight and drag penalties. Even small five-hole probes can add significant weight and drag penalties, causing a noticeable performance degradation.

Flush air data sensing (FADS) systems are a particular method based upon pressure measurements at locations on the surface of the aircraft. There has been extensive research into this method for aircraft and spacecraft. NASA research reports $[12,13]$ designed flush systems for air data measurements onboard the Space Shuttle and X-33 space vehicles during re-entry. Flight tests on manned aircraft like the F-14 [14] and KC-135 [15] validate the FADS technique. These results demonstrate the feasibility of the FADS approach even during maneuvering flight.

Later on, FADS systems were implemented alongside neural networks with increasing success. Crowther and Lamont [16] examined different pressure port configurations over a general fighter fuselage through wind tunnel testing. Calia et al. [17] computed static pressure and mach number of a M-346 jet trainer with neural networks and a FADS setup, using wind tunnel runs as well as flight test data to train and test the neural networks. Rohloff et al. [18] employed a FADS system on the nosecone of a F-18 to compute wind parameters. Neural networks were specifically chosen for the FADS system because they can handle large sets of flight test data without explicit knowledge of the airflow model over the nosecone.

While all of the previous work in neural network based FADS systems has proven its accuracy and usefulness in large, fast aircraft with expensive instrumentation, few have looked at adapting the method for small UAVs. Coupled with inexpensive commerical grade pressure sensors, the approaches proven in the larger aircraft can be scaled down in the hope of creating a small,versatile, low-cost system for wind sensing. This type of application is not without precedent as Samy et al. [19] described a wing-installed FADS setup for measuring airspeed and angle of attack, but was not capable of sensing angle of sideslip.

This paper discusses the development and implementation of a nosecone mounted flush air data sensing system intended for use on small, low-cost, soaring UAVs. It uses readily available pressure sensors and microcontrollers to sense airspeed, angle of attack, and angle of sideslip. Theoretical aspects for surface pressure measurement are discussed and compared with wind tunnel tests at speeds ranging from $9 \mathrm{~m} / \mathrm{s}$ to $27 \mathrm{~m} / \mathrm{s}$. Neural networks use this wind tunnel data to develop regression models to compute air data from surface pressure measurements. The models are then applied to simple glide tests to evaluate qualitative 
performance.

\section{Design of Wind Sensing System}

The objective of the wind sensing system is to determine the wind vector of a glider, even during soaring maneuvers. Dynamic soaring techniques offer huge potential for extending the endurance of small UAVs, but require precise knowledge of the aircraft's speed and orientation in the wind field to be successful. The wind sensor must provide airspeed $\left(V_{a}\right)$, angle of attack $(\alpha)$, and angle of sideslip $(\beta)$ to the soaring controller, which can then estimate the wind gradient. Additionally, the design must minimize the size, weight, and complexity of the sensing system for easy implementation on small UAVs' constrained flight control systems.

Right in line with the beaks of albatrosses, flush air data sensing systems detect changes in wind speed and direction with differential pressure readings between ports. A nosecone based FADS system proved most desirable compared to other wind sensors because it offered good potential from the least invasive method. The tip of the nose is very close to a spherical shape and can be approximated as such for easier flow analysis, a conclusion supported by Samy et al. [19]. Unlike Samy's wing-based FADS systems, a noseconebased system keeps the pressure ports in unobstructed flow for better sideslip measurements during harsh maneuvers. Flush systems also minimize the external footprint and prove more resilient to belly and rough landings when compared to externally mounted probes or vanes.

\section{A. Theoretical Background}

Nosecones are generally not hemispheres, but an analysis of surface pressure on a hemisphere using potential flow can provide an indication of the magnitude of expected surface pressure differentials. This can then be used to compute the optimal geometry of pressure ports (to maximize sensitivity) and compute required sensor specifications.

For a sphere in potential flow, surface pressure at a particular location depends on the angle between the stagnation point and that location:

$$
P_{s}=P_{\infty}+q_{\infty}\left(1-\frac{9}{4} \sin ^{2} \sigma\right)
$$

The corresponding pressure coefficient is:

$$
C_{p}=1-\frac{9}{4} \sin ^{2} \sigma
$$

where $\mathrm{P}_{s}$ is the surface pressure at a location on the sphere, $\mathrm{C}_{P}$ is the corresponding pressure coefficient, $\mathrm{P}_{\infty}$ is the freestream static pressure, $\mathrm{q}_{\infty}$ is the freestream dynamic pressure, and $\sigma$ is the angle from the stagnation point on the front of the sphere to the location on the sphere.

For a sphere with a pressure port located at some latitude $\phi_{i}$ and longitude $\lambda_{i}$ (defined with respect to a body coordinate system $x y z$ - see Figure 2), this angle $\sigma_{i}$ is a function of angle of attack $\alpha$ and angle of sideslip $\beta$, and can be computed using the haversine formula:

$$
\sigma_{i}=2 \sin ^{-1} \sqrt{\sin ^{2}\left(\frac{\alpha-\phi_{i}}{2}\right)+\cos \alpha \cos \phi_{i} \sin ^{2}\left(\frac{\beta-\lambda_{i}}{2}\right)}
$$

The difference in pressure coefficient between two ports located at $\phi_{i}, \lambda_{i}$ and $\phi_{j}, \lambda_{j}$ on the sphere is thus

$$
\Delta C_{P i j}=\frac{9}{4}\left(\sin ^{2} \sigma_{i}-\sin ^{2} \sigma_{j}\right)
$$

and the difference in pressure between the two ports is

$$
\Delta P_{i j}=P_{i}-P_{j}=\frac{9}{4} q_{\infty}\left(\sin ^{2} \sigma_{i}-\sin ^{2} \sigma_{j}\right)
$$

This is a function of $\alpha, \beta$ and $V_{a}$. Thus to compute the three desired quantities $V_{a}, \alpha$ and $\beta$ requires at least three differential pressure measurements. A brief, simplified discussion on pressure port selection to maximize sensitivity is presented. 


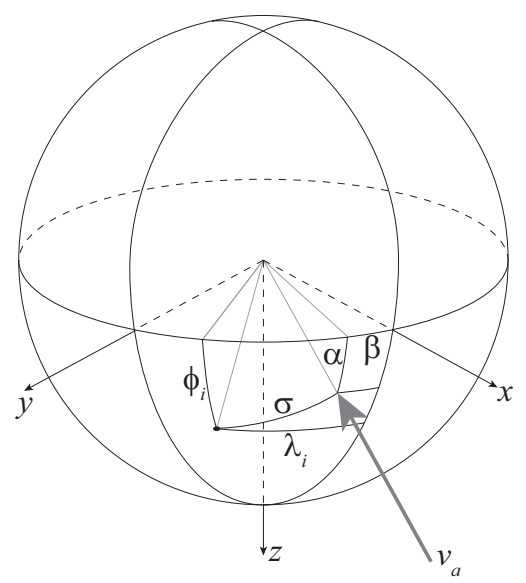

Figure 2. Coordinates for a sphere in uniform potential flow

Typically one of the differential pressure measurements will be taken between a port located at $(\phi, \lambda)=$ $(0,0)$ and a static pressure reference so that $q_{\infty}$ can be computed. Airspeed $V_{a}$ is computed from $q_{\infty}$ given density.

To measure angle of attack consider two ports located on the prime meridian (i.e. at $\lambda=0$ ) at latitudes $\phi_{1}$ and $\phi_{2}$. Equation 3 shows that sideslip $\beta$ does have a small effect on $\sigma_{i}$, but for small sideslip this can be ignored. The pressure differential due to angle of attack $\alpha$ is

$$
\Delta P_{21}=\frac{9}{4} q_{\infty}\left(\sin ^{2}\left(\alpha-\phi_{2}\right)-\sin ^{2}\left(\alpha-\phi_{1}\right)\right)
$$

Rearranging gives

$$
\Delta P_{21}=\frac{9}{4} q_{\infty} \sin (2 \alpha-2 \bar{\phi}) \sin \Delta \phi
$$

where $\bar{\phi}=\frac{\phi_{1}+\phi_{2}}{2}$ and $\Delta \phi=\phi_{1}-\phi_{2}$. Maximum sensitivity to changes in $\alpha$ occurs when $\frac{\partial \Delta P}{\partial \alpha}$ is maximized:

$$
\frac{\partial \Delta P}{\partial \alpha}=\frac{9}{2} q_{\infty} \cos (2 \alpha-2 \bar{\phi}) \sin \Delta \phi
$$

By inspection, this is maximized when $\Delta \phi=\frac{\pi}{2}\left(90^{\circ}\right)$ and $\bar{\phi}=\alpha$. Placing ports at $\phi= \pm \frac{\pi}{4}\left( \pm 45^{\circ}\right)$ will thus give maximum sensitivity near an angle of attack of $0^{\circ}$ and almost (but not quite) decouple the pressure differential from sideslip. The same can be done for measuring sideslip, resulting in ports at $\lambda= \pm 45^{\circ}$. Figure 3 shows variation in $\Delta C_{P}$ for pressure ports located on the prime meridian at $\phi= \pm 45^{\circ}$ and on the equator at $\lambda= \pm 45^{\circ}$ as both $\alpha$ and $\beta$ vary.

These equations can aid in calibration of a traditional five-hole probe, but in practice wind tunnel calibration over a range of airspeeds is used since the potential flow analysis ignores the effects of viscosity (and hence flow separation).

These equations can also give an estimate of the expected pressure differentials as flight conditions change. For example, at an airspeed of $10 \mathrm{~m} / \mathrm{s}$ at standard sea level conditions $\left(\rho=1.225 \mathrm{~kg} / \mathrm{m}^{3}\right), q_{\infty}=122.5 \mathrm{~Pa}$. Figure 3 shows that $\Delta C_{P}$ varies from roughly -1.5 to +1.5 as $\alpha$ varies from $-20^{\circ}$ to $+20^{\circ}$, so $\Delta P$ will vary from roughly $-180 \mathrm{~Pa}$ to $180 \mathrm{~Pa}$. From Equation 8 the sensitivity near $\alpha=0$ at this airspeed is $551 \mathrm{~Pa} / \mathrm{rad}$ (9.6 $\mathrm{Pa}$ /degree). This can guide selection of pressure sensors.

\section{B. Implementation}

A prototype FADS system was design and implemented on a NESailplanes Omega II glider, seen in Figure 4. The Omega II is a self-launching, radio-controlled sailplane and the nosecone FADS system necessitated the removal of the electric motor. While the absence of the motor prevents self-launching, it is not necessary for flight and the aircraft can still be thrown or launched on a hi-start. The parameters of the aircraft are given in Table 1. For comparison, the aircraft properties are listed alongside those of dynamic soaring Procellariiform species. 


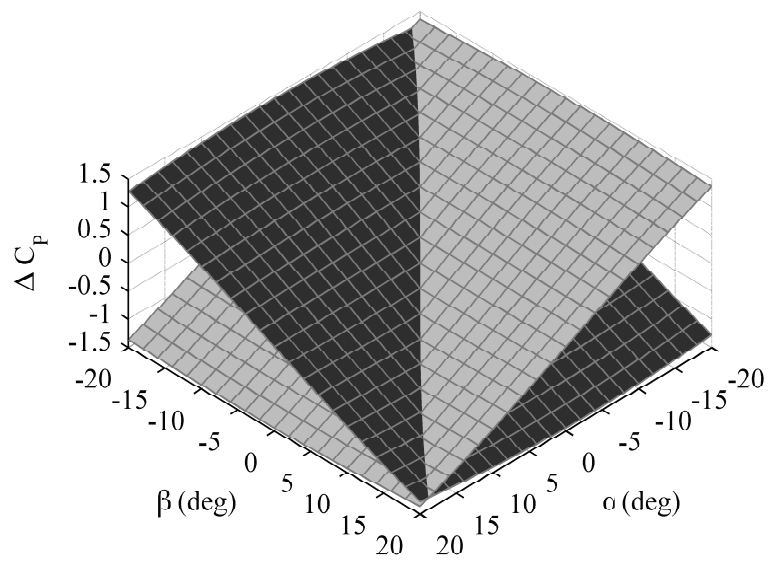

Figure 3. Variation in $\Delta C_{P}$ with angle of attack and angle of sideslip. The light colored surface shows $\Delta C_{P}$ for ports on the meridian as angle of sideslip changes; the dark surface shows $\Delta C_{P}$ for ports on the equator as angle of attack changes.

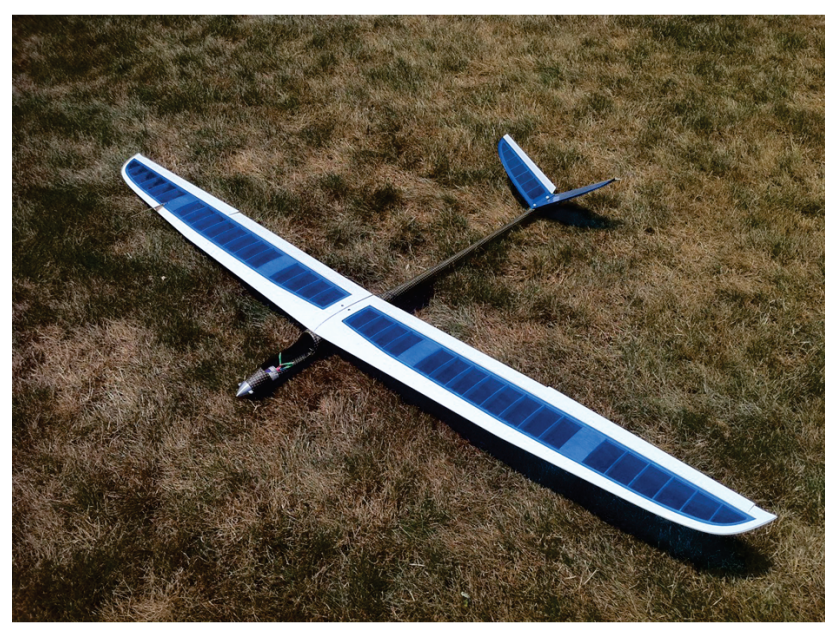

Figure 4. Unmodified Omega II 2-meter powered sailplane.

The overall design is kept simple for affordability while still maintaining the necessary accuracy. Crashes are inevitable so the system uses readily available pressure transducers to prevent the cost of the FADS sensors from dwarfing the cost of the aircraft itself. This also enables portions of the system to be readily swapped out as better sensors become available or new designs are fabricated.

The nosecone was fabricated using a rapid prototyping machine with the aircraft's original spinner as the template. The shape was stretched from the original spinner to a more hemispherical shell. The main shell defines the curvature of the nosecone and contains the pressure ports. Due to the small size of the nosecone $(4.175 \mathrm{~cm}$ diameter by $4 \mathrm{~cm}$ long) only five pressure ports could feasibly fit on the shell. One port is located at the tip of the nose while the remaining four are evenly distributed over the cone at roughly $45^{\circ}$ angles. The pressure ports were created with $\frac{1}{8}$ inch pilot holes normal to the surface before small $\frac{5}{32}$ inch OD, $\frac{3}{32}$ inch ID by $5 \mathrm{~cm}$ long brass tubes were inserted into the pilot holes, flush with the external surface. Flexible $\frac{1}{8}$ inch ID tygon tubes were then sealed to the brass tubes to connect to the pressure transducers. These small tubes are used to maximize available space within the shell and Paces et al. [20] demonstrated that small port holes approximately this size have minimal difference in output signals compared to larger ports. The five ports also created the need for a sixth port for static pressure measurement. An appropriate static port location was found using a panel method model of the aircraft and two static pressure ports were drilled into the airframe at mirror locations in the front fuselage area.

The nosecone is made in two halves with the main shell containing the pressure holes and a backing 
Table 1. Properties of the Omega II and Procellariiform species [10].

\begin{tabular}{cccccc}
\hline \hline Name & mass $(\mathrm{kg})$ & span $(\mathbf{m})$ & chord $(\mathbf{m})$ & area $\left(\mathbf{m}^{2}\right)$ & $\mathbf{A R}$ \\
\hline Omega II & 1.2 & 2.0 & 0.153 & 0.305 & 13.1 \\
Black-browed Albatross & 3.08 & 2.19 & 0.162 & 0.354 & 13.5 \\
White-chinned Petrel & 1.08 & 1.41 & 0.118 & 0.167 & 11.9 \\
\hline \hline
\end{tabular}

that mounts to the firewall using existing screw holes for the motor. Separation of the two is necessary to access the inside of the shell to feed the tygon tubes through. After finishing the connections, the halves lock together and are sealed. The finished design is pictured in Figure 5.
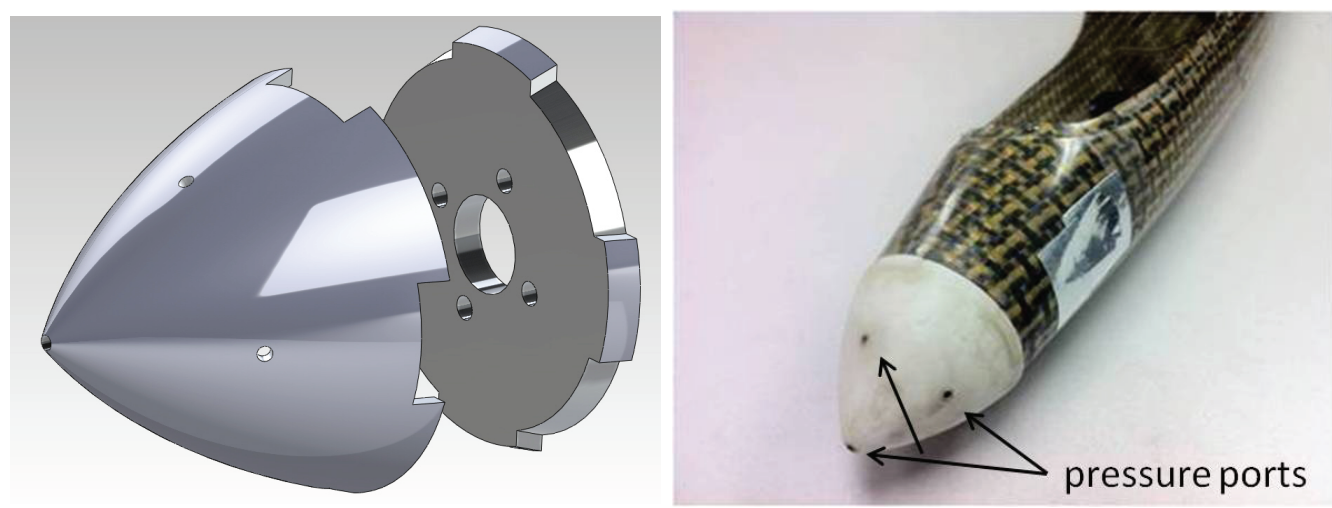

Figure 5. FADS nosecone

Two different pressure transducers are considered for use in the FADS system: Honeywell HSCDRRN002NDAA3 and Freescale MPXV7002DP. The specifications for each sensor are presented in Table 2. The Honeywell sensor is better suited to the expected pressure differential and has better response time and sensitivity. The Freescale sensor, while slightly limited in performance, is simpler, more widely available, and lower cost. Freescale sensors have also been successfully used in similar wind vector sensing systems [20,21]. Ultimately, the Freescale transducers are chosen over Honeywell sensors for their ease-of-integration and the fact they can be easily and cheaply replaced when damaged. The FADS system presented in the paper is intended as a first attempt at the method and multiple iterations and flight crashes are expected so adaptability of the system is pursued at the cost of reduced resolution.

Table 2. Differential pressure transducers.

\begin{tabular}{lcc}
\hline \hline parameter & Freescale & Honeywell \\
\hline price & $\$ 19.99$ & $\$ 51.25$ \\
operating range & $\pm 2000 \mathrm{~Pa}$ & $\pm 500 \mathrm{~Pa}$ \\
supply voltage & $5 \mathrm{~V}$ & $3.3 \mathrm{~V}$ \\
supply current & $10 \mathrm{~mA}$ & $1.6 \mathrm{~mA}$ \\
signal output & $0.5-4.5 \mathrm{~V}$ & $0.33-2.97 \mathrm{~V}$ \\
accuracy & $0.1 \mathrm{~V}$ & $0.066 \mathrm{~V}$ \\
response time & $1 \mathrm{~ms}$ & $0.46 \mathrm{~ms}$ \\
\hline \hline
\end{tabular}

Differential pressure measurements from the three pressure transducers are combined by a microcontroller to compute airspeed, angle of attack, and angle of sideslip. An ArduPilot Mega is used as the air data computer for the FADS system. ArduPilots are inexpensive single board microcontrollers specifically designed for use in small UAVs that can be used for flight control and are a good platform for expansion. The ArduPilot receives the raw analog pressure signal from the transducers and computes the air data for 
transmission to another computer or internal use for flight control, as pictured in Figure 6.

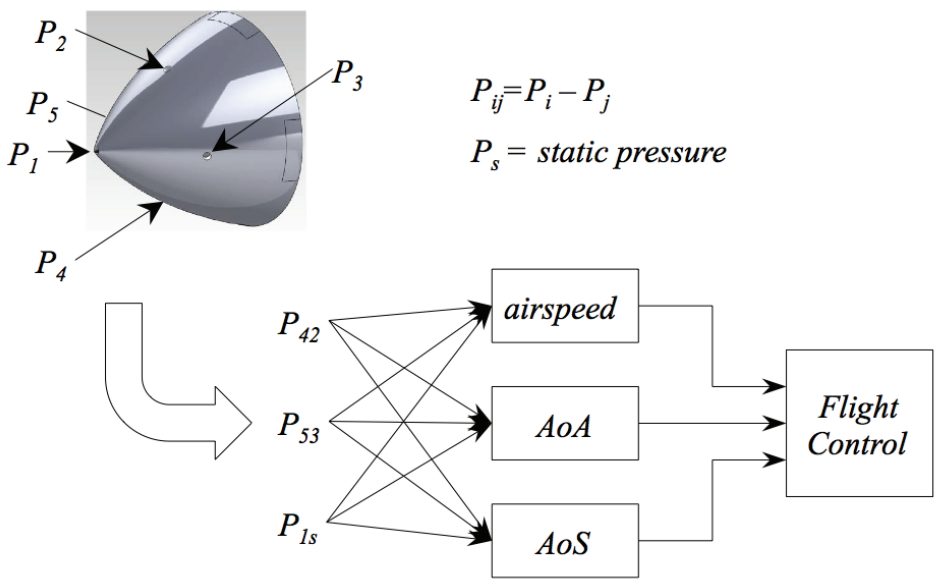

Figure 6. Diagram of flush air data sensing system.

\section{Wind Tunnel Testing}

The completed FADS system is installed on the Omega II airframe and placed in a wind tunnel to collect calibration data. While the spherical potential flow equations provide predictions with enough accuracy to select appropriate sensor components, they do not have enough accuracy for use in the air data computer. Instead, large sets of pressure readings from the Freescale transducers are taken from wind tunnel tests at various airspeed and angular positions. Different regression techniques can then be applied to the training data to capture the surface pressure to air data function.

The raw training data was collected from wind tunnel tests taken in the Pennsylvania State University's low turbulence, subsonic wind tunnel with a $3.25 \times 5$ foot test section, seen in Figure 7 . For the tests, the airframe was mounted to a motorized test stand to control $\alpha$ and $\beta$ deflections. Since the 2 meter wing could not fit within the section, two reinforced foam wings, 52 and 79 centimeters span, were cut out with the aircraft's MH-32 airfoil. The inner portion of the wing had to be included because of its effect upon the static pressure port, although the absence of the extreme outer tips of the wings are assumed to have negligible effect on the pressure readings.

The wind tunnel tests were performed at airspeeds of $9 \mathrm{~m} / \mathrm{s}$ to $27 \mathrm{~m} / \mathrm{s}$ in approximately $1 \mathrm{~m} / \mathrm{s}$ increments. These airspeeds correspond to the expected dynamic soaring flight regime of the aircraft. During maneuvers, albatrosses can reach up to $25 \mathrm{~m} / \mathrm{s}$ in dives [10] while the Omega II will stall below $7 \mathrm{~m} / \mathrm{s}$. At each airspeed, the pressure readings were taken in $1^{\circ}$ increments from $-15^{\circ} \leq \alpha \leq 15^{\circ}$ and $-15^{\circ} \leq \beta \leq 15^{\circ}$. A few additional runs were taken in $0.5^{\circ}$ increments and were included along with the standard runs. Dynamic tests were also performed alongside the static data measurements, but were not used for the training data. Rate tests moved the aircraft through $\alpha$ and $\beta$ deflections at various rates while dynamic step tests were performed in the same manner as the standard $\alpha, \beta$ steps, but with transient behavior fully captured.

Airspeed was controlled with wind tunnel throttle setting. The throttle setting remained fixed throughout the test run while calibrated pressure transducers along the test section recorded dynamic pressure. The airframe position was controlled using two stepper motors commanded through LabView. A LabView code was setup to automatically sweep the aircraft through the $\alpha$ and $\beta$ deflections and record the necessary values at the particular location. Upon reaching the desired location, the code recorded the $\alpha, \beta$ positions, collected 101 data points from the wind tunnel pressure transducers, and recorded 101 data packets containing $V_{a}, \alpha$, $\beta$, and a checksum from the Ardupilot. This whole process lasts roughly 2 seconds at each location. Every 5 minutes, wind tunnel static pressure and temperature were manually recorded to correct for air density changes inside the test section when converting dynamic pressure to airspeed. The collection of wind tunnel pressure transducer measurements at each data location allowed for blockage effects in the tunnel airspeed at high $\alpha, \beta$ deflections to be taken into account.

The majority of the wind tunnel data was taken with the $79 \mathrm{~cm}$ span wing; however, at $20 \mathrm{~m} / \mathrm{s}$, the 


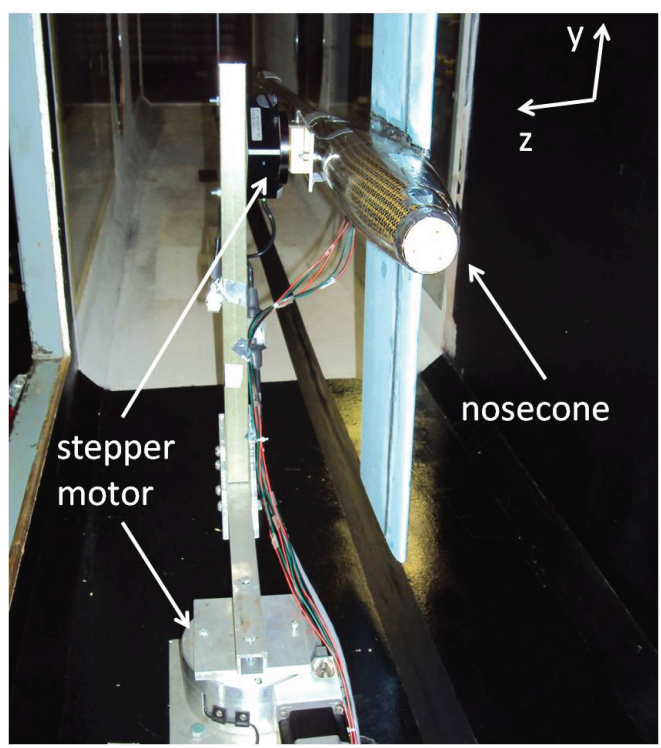

Figure 7. The aircraft mounted in the wind tunnel.

wing produces too much lift for the motor controlling $\alpha$ deflections. The motor stalled at $10^{\circ} \alpha$ and stopped moving. To increase the speed range, the $\alpha$ deflections were limited to a maximum of $0^{\circ}$ up until $24.5 \mathrm{~m} / \mathrm{s}$. After this, the $52 \mathrm{~cm}$ wing was installed, allowing full range of $\alpha$ deflections from $19 \mathrm{~m} / \mathrm{s}$ until $25 \mathrm{~m} / \mathrm{s}$. From $25 \mathrm{~m} / \mathrm{s}$ to $27 \mathrm{~m} / \mathrm{s}$, the $\alpha$ deflections had to be truncated again. The intentions were to explore the full range of deflections until $30 \mathrm{~m} / \mathrm{s}$, but the testing equipment could not exceed $27 \mathrm{~m} / \mathrm{s}$. After examination, there were no noticeable differences between the data taken from the 79 and $52 \mathrm{~cm}$ wings, so both sets of data were included in the training set.

\section{A. Comparison to Potential Flow}

Although the predictions from the potential flow model can not be directly used to compute the wind vector, a comparison between the predictions and the wind tunnel measurements indicate the general accuracy and applicability of the models for design use. Comparison between the two validates the assumptions and checks for unexpected or unreasonable behavior. The difference in pressure coefficients given angle of attack and angle of sideslip variations are plotted in Figures $8(\mathrm{a})$ and $8(\mathrm{~b})$. Figure $8(\mathrm{a})$ shows the predicted $\Delta C_{p}$ for ports located at $\pm 45^{\circ}$ on the meridian of a sphere and the measured difference on the actual FADS nosecone as angle of attack is varied. Figure $8(\mathrm{~b})$ compares the $\Delta C_{p}$ for ports at $\pm 45^{\circ}$ on the equator of the sphere and the nosecone for $\beta$ deflections.

Th results show qualitatively similar behavior between the potential flow predictions and the wind tunnel measurements, but with slight differences. In Figure 3, change in pressure coefficient is independent of q; however, in Figure $8, \Delta C_{p}$ does indeed vary with q. This discrepancy can be attributed to a variety of factors including Reynolds number effects, the ogive shape, and the influence of the wing upon static pressure measurements at different $\alpha$. This discrepancy confirms that wind tunnel or flight data needs to be collected for correct FADS calibration. Despite the difference, both the model and the measurements demonstrate the same general behavior, indicating that the potential flow model is useful for "rule-of-thumb" conclusions.

\section{B. Training Set Creation}

The training data set was created out of the wind tunnel data at all airspeeds with angular positions between $-5^{\circ} \leq \alpha \leq 12^{\circ}$ and $-6^{\circ} \leq \beta \leq 6^{\circ}$. These values correspond to the expected operating region of the aircraft. Including the extraneous outside data within the training set could adversely affect the performance of the regression models within the operating range. Ardupilot data packets that fail to pass the checksum were removed along with unreasonable measurements that otherwise pass the checksum verification, ie when a sensor disconnected. 


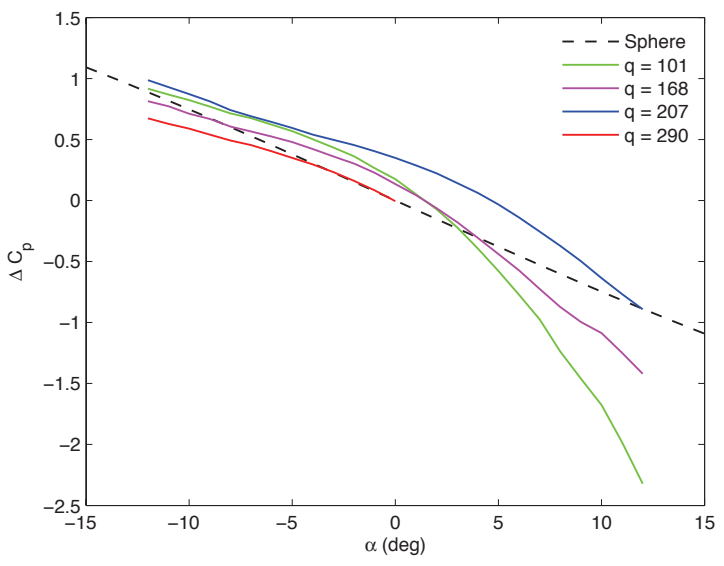

(a) Angle of Attack

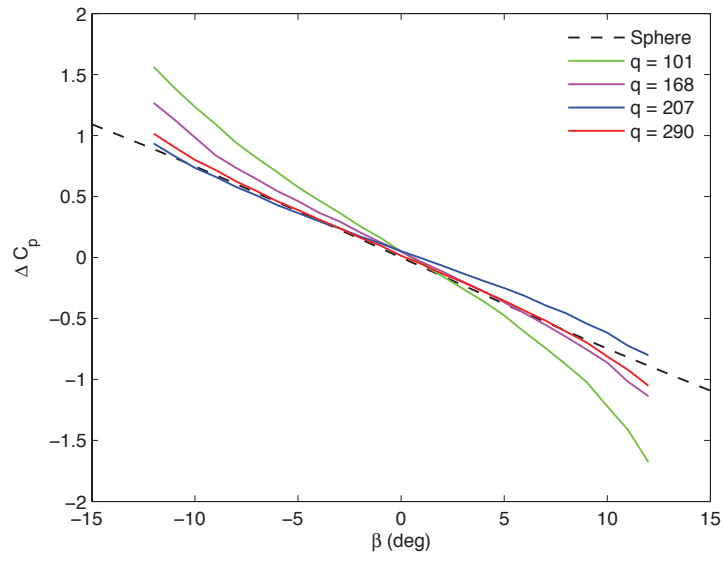

(b) Angle of Sideslip

Figure 8. Variation in measured pressure coefficient for FADS at varying dynamic pressures compared with potential flow over a sphere.

Rather than use all 101 data points, the remaining wind tunnel pressure transducer readings and FADS differential pressure sensor measurements are averaged at each $\alpha, \beta$ location. This also serves to remove noise from the regression analysis. The mean FADS readings are shifted to center the pressure differentials at 0 and subsequently normalized to fall within $+/-1$. The resulting mean pressure readings span -0.2726 to 0.8288 . The differential pressure readings are concatenated to create a $4648 \times 3$ input data matrix. Three separate target vectors for $V_{a}, \alpha$, and $\beta$ correspond to the input matrix. The airspeed target vector is left in $\mathrm{m} / \mathrm{s}$ units while the true $\alpha$ and $\beta$ position are converted to radians.

\section{Regression Analysis}

Multiple methods can be used to calculate the airspeed, angle of attack, and angle of sideslip parameters given surface pressure measurements. One particular method is direct function fitting to the data. While the potential flow equations are not invertible, a system of equations involving the pressure readings can accurately capture the wind vector. The appropriate coefficients are then extracted using the training data. Some cases have coupled this method with Kalman Filters for improved performance [22]. Lookup tables are a second method capable of accurately computing the wind vector from large sets of stored training data. The $V_{a}, \alpha$, and $\beta$ values are interpolated from large 3D tables with either full or subsets of the training data. This method has been used before in FADS and conventional probe systems [23].

Although these methods have been used successfully for air data computation in the past, they are illsuited to this particular application. Direct function fitting requires priori knowledge of the measurements equations and the order and the results in Figure 8 demonstrated the actual viscous flow equations are poorly understood. Lookup tables do not require this explicit knowledge, but do need large data tables to be stored on the computer. In order to adequately cover the dynamic flight regime of the Omega II, substantially large subsets of the training data will need to be incorporated in the Arduino microcontroller. A more compact, but model-free representation of the function of surface pressure to air data is necessary.

Neural networks present the ideal solution to create nonlinear regression models without prior knowledge of the function or stored large lookup tables. The wind tunnel data is used to train the numerous weights of biases associated with each layer of neurons. This training process acts as a black box method to simply create a function mapping the surface pressure measurements to the actual wind vector. Neural networks have been used before in FADS systems and multihole probes due to their applicability with large data sets [16-19]. The resulting networks demonstrated high levels of accuracy even in wide ranges of maneuvering flight. 


\section{A. Neural Network Model}

The normalized data from the pressure transducers are directly sent into the neural networks. Various configurations involving Radial Basis Functions and Single Hidden Layer (SHL) networks were examined, but only Single Hidden Layer networks are presented hereafter. Different arrangements of the SHL neural networks were explored. One arrangement uses a combined output model with all three wind vector parameters $\left(V_{a}, \alpha, \beta\right)$ output from a single network. This compares against three separate networks each independently computing only one of the parameters. Both arrangements use the same total number of neurons, ie 3 neurons in 3 separate networks compared against 9 neurons in a single network. Interestingly enough, this separation did affect the accuracy of the output.

The general structure of the airspeed neural network is seen in Figure 9(a) and the remaining two networks follow the same architecture. The three inputs from the pressure sensors are sent to each network's input layer of $\mathrm{N}$ neurons. Each neuron in the input layer is connected to every neuron in the hidden layer as well. The hidden neurons are connected to a single output neuron which outputs the desired wind vector parameter. This structure results in a $\mathrm{N} \times 3$ weighting matrix in the input layer, a $1 \mathrm{x} \mathrm{N}$ weighting matrix in the hidden layer, a $\mathrm{N}$ x 1 bias vector in the input layer, and a 1 x 1 scalar bias in the hidden layer. The corresponding combined network is pictured in Figure 9(b). The matrices and vectors in this arrangement have $3 \mathrm{~N}$ components to maintain the same total size. In both arrangements, the hidden layer uses tan-sigmoid activation functions and the output layers use simple linear functions.

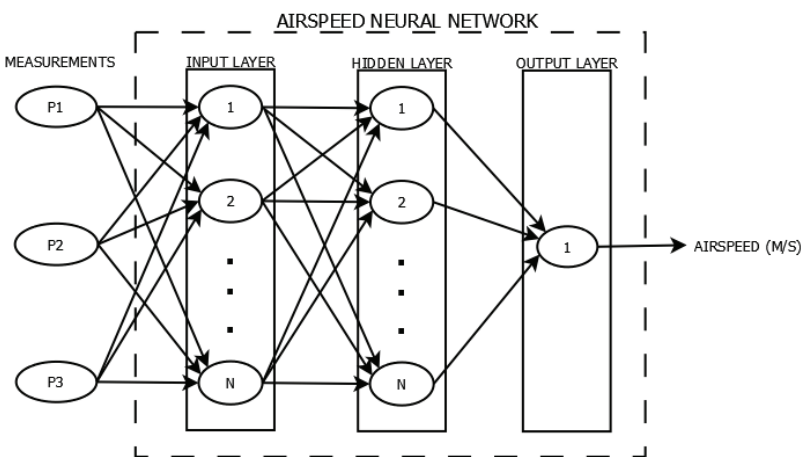

(a) Single Output

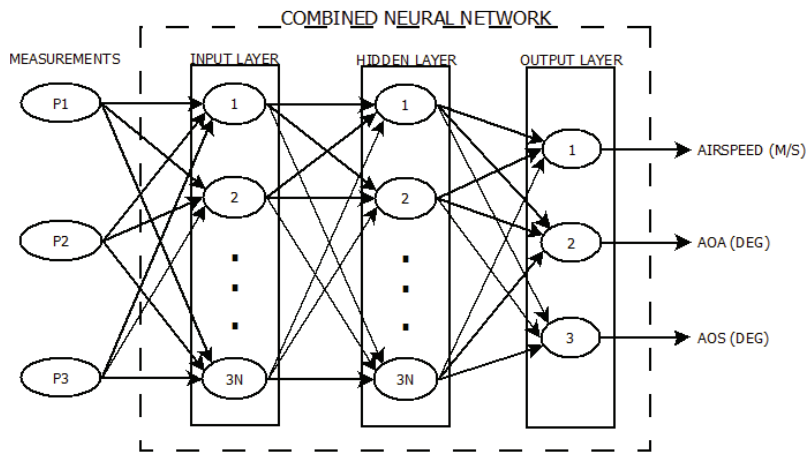

(b) Combined Output

Figure 9. The generalized structure of the airspeed neural network with $\mathbf{N}$ neurons in the input and hidden layers alongside the structure of the combined neural network with $3 \mathrm{~N}$ neurons in the layers. The $\alpha$ and $\beta$ networks follow the same structure as the airspeed network.

Multiple versions of the SHL neural networks were investigated, each with a different number of neurons in the input and hidden layers. Although various numbers of neurons were analyzed, the numbers $\mathrm{N}=3,9$, 15, 30 and 45 were the primary focus of the performance analysis. As the number of neurons increases, the complexity and memory requirement also increases. With three coupled inputs, $\mathrm{N}=3$ neurons represented the simplest neural network with acceptable accuracy. The number of neurons was arbitrarily capped at $\mathrm{N}=45$ to keep the complexity of the regression model down. Higher order dynamics are not expected in the air data equations. Likewise, although the ArduPilot Mega has more than enough memory to store the parameters, subsequent iterations of the design will attempt to minimize the size of the FADS system and smaller microcontrollers with less memory might be used instead.

\section{B. Results of Wind Tunnel Based Training}

The neural networks were trained using the Levenberg-Marquardt back-propagation algorithm in the Matlab Neural Network Toolbox [24]. Each network was retrained heuristically until the performance didn't improve. The training data was randomly broken up into three sections, $70 \%$ for training, $15 \%$ for validation, and $15 \%$ for independent performance testing. The first two sections are used during the training process while the third set is separate from the training process.

The root mean square error (RMSE) of the neural network models applied to the independent testing subset is presented in Table 3. This subset contains random samples from the entire airspeed range of 9 
$\mathrm{m} / \mathrm{s}$ to $27 \mathrm{~m} / \mathrm{s}, \alpha$ range of $-5^{\circ}$ to $12^{\circ}$, and $\beta$ range of $-6^{\circ}$ to $6^{\circ}$. The first five rows in the table correspond to the single output, separate network arrangement. Not surprisingly, the more complex systems perform the best, although the airspeed network RMSE shows clear convergence. The angle of attack and angle of sideslip networks converge much more slowly with the $\beta$ performance noticeably better than $\alpha$. This faster convergence is possibly due to the symmetry of the aircraft across the xz plane. The last row in Table 3 details the RMSE performance of a combined three output network corresponding to the $\mathrm{N}=30$ networks in row four. The sets of separate networks consistently outperform the combined output networks for every $\mathrm{N}$ value; the $\mathrm{N}=30$ is only listed in the table as an example.

Table 3. Root mean square error of neural network output. The performance corresponds to an independent testing subset randomly selected from the wind tunnel training data.

\begin{tabular}{cccc}
\hline \hline Neurons & V (m/s) & AoA (deg) & AoS (deg) \\
\hline 3 & 0.250 & 1.36 & 0.413 \\
9 & 0.2270 & 0.7793 & 0.2703 \\
15 & 0.2058 & 0.7427 & 0.2204 \\
30 & 0.1766 & 0.5362 & 0.1659 \\
45 & 0.1865 & 0.4067 & 0.1535 \\
\hline Combined & 0.1725 & 0.9908 & 0.4148 \\
\hline \hline
\end{tabular}

Figures 10 and 11 show errors in computed air data at wind tunnel speeds of $20 \mathrm{~m} / \mathrm{s}$ and $10 \mathrm{~m} / \mathrm{s}$, respectively. These airspeeds are chosen to compare performance at low and relatively high flight speed ranges. For each case, the airspeed is held nominally constant with slight variations owing to blockage effects at high $\alpha, \beta$ values. The angle of attack is varied from $-5^{\circ} \leq \alpha \leq 12^{\circ}$ in $1^{\circ}$ increments as $\beta$ is held constant for a number of $1^{\circ}$ steps from $0^{\circ} \leq \beta \leq 6^{\circ}$. The sideslip behavior is assumed to be constant due to the xz symmetry of the aircraft so only half the data is shown.

The results in Figures 10 and 11 identify certain peculiarities with the neural network regression models. All the networks have the same general trend in Figure 10(a), although the more complex models have less error. The $\mathrm{N}=30, \mathrm{~N}=45$, and combined network models all converge to the same trendline, but still exhibit the same error, indicating the network reached the maximum possible performance. This error changes with $\alpha$ and $\beta$ and can be representative of unmodeled dynamics. Meanwhile, Figures 10(b) and 10(c) show roughly no bias and a clear improvement in accuracy as the number of neurons increases. The figures also demonstrate the poor performance of the combined network. Even though the total number of neurons is the same as the $\mathrm{N}=30$ set of networks, the performance is worse than even the $\mathrm{N}=9$ network model for $\alpha$ and $\beta$, especially in regards to Figure 10(c). This appears to be due to overfitting of the data.

Lower airspeed results are pictured in Figure 11. Just as in Figure 10, the same general trends are observed although slight differences in biases occur between the two nominal airspeeds. The bias observed in Figure 10(a) has lessened in Figure 12(a) while slight $\alpha$ bias develops for lower neuron models in Figure 12(b). Figure 12(c) also demonstrates a bias as a function of $\beta$. These discrepancies between the models at different airspeeds highlights the inherent difficulty of accurately modeling the wind vector given the low performance sensors. While these results do show the limitations of the nonlinear regression models, the overall accuracy of the system is proven through the evaluations.

\section{Network Comparison}

The $\mathrm{N}=30$ and $\mathrm{N}=45$ regression models outperform the simpler models, more noticeably in the $\alpha$ calculations than in the airspeed or $\beta$ calculations. The lesser neuron models may benefit from the symmetry of the aircraft across the xz plane to improve their performance. Across the board, the $\mathrm{N}=30$ or 45 neuron networks are most desirable because of their demonstrated improvement in accuracy. In particular, the $\mathrm{N}=$ 30 models give very good general accuracy for their complexity with RMSE performance under $0.2 \mathrm{~m} / \mathrm{s}$ in airspeed, $0.6^{\circ}$ in angle of attack, and $0.2^{\circ}$ in angle of sideslip when compared with the wind tunnel data.

Despite the increase accuracy of the more complex model, the simpler $\mathrm{N}=9$ neuron networks might prove more desirable in certain situations. The complete set of $\mathrm{N}=30$ regression models includes a total of 453 parameters, 151 in each model, that need to be stored, whereas the simpler $\mathrm{N}=9$ networks only require 138 parameters. The Ardupilot Mega used in the tests has more than ample capacity to use the $\mathrm{N}=30$ or 
45 neuron neural network models, but 9 neuron models demonstrate acceptable capability, especially in the cruise regime, if smaller models are necessary.

\section{Flight Test Results}

Simplified flight tests were conducted with the FADS-equipped Omega II sailplane to evaluate the qualitative performance of the FADS system. An independent wind vector sensor could not be included on the small aircraft, so a GPS receiver was installed to provide some form of validation to compare regression model performance. While the GPS measurements are only available at $1 \mathrm{~Hz}$, the groundspeed measurements in particular give insight into the accuracy of the results in real-world conditions. The aircraft was flown in the early daylight hours to minimize wind and hand-launched off of a hill to give longer flight times.

The pressure data was processed by the $\mathrm{N}=30$ neuron models and the raw, unfiltered output at the Arduino sample rate of $200 \mathrm{~Hz}$ is discussed below. Before use with the soaring controller, these FADS computations should be filtered and downsampled to avoid issues with Nyquist sampling rate. The transducer pressure measurements are normalized in the same manner as the wind tunnel data for consistency. Unexpectedly, the three pressure readings from the transducers were shifted consistently by a constant number of counts when compared to the wind tunnel measurements. The pressure readings taken while the vehicle was at rest showed a constant bias when compared to data in the wind tunnel while at rest. While the cause of this is unknown, the flight test data was simply shifted down by this known bias to match pressure readings taken while at rest.

\section{A. Steady Glide}

The $V_{a}, \alpha$, and $\beta$ computations for a steady gliding flight are shown in Figure 12. The initial few seconds occur during hand launching and the rapid movements correspond to pilot maneuvers to level off the airplane. The remainder of the flight had minimal pilot input except minor corrections to level the aircraft.

The airspeed computation is compared against the GPS groundspeed and both demonstrate similar trends. The FADS calculations show more fluctuations, although any transient responses would not be picked up by the $1 \mathrm{~Hz}$ GPS measurements. Angle of attack is compared against the expected $\alpha$ value for a steady glide at the measured groundspeed and both shown the same general trend. The computed angle of attack increases as expected when the airspeed decreases towards the end of the flight. Angle of sideslip remains fairly constant throughout the flight with a small bias to negative $\beta$. All three neural network outputs demonstrate a close correlation to the measured or expected values.

\section{B. Longitudinal Response}

The $\alpha$ output to a pilot-induced elevator doublet is seen in Figure 13. The elevator was deflected downwards for a nose down moment at 5.5 seconds before an up elevator command. The process was repeated at 9.5 seconds into the flight. While the $\alpha$ calculation shows a distinct bias when compared to expected cruise $\alpha$, the sudden change in pitch from the doublet is reported by the sensor. Additionally, the $\alpha$ computed from groundspeed is only valid for steady state flight, which is not the case here. After the elevator doublet, subsequent pilot inputs to stabilize the aircraft are recorded as $\alpha$ fluctuations.

\section{Directional Response}

Figure 14 illustrates the $\beta$ calculation during a rudder doublet maneuver. Unlike the other two wind parameters, there is no ready way to valid $\beta$ deflections, although it is assumed the aircraft flies with zero sideslip on a calm day with undisturbed flight. The first rudder doublet is initiated with a left rudder command 5 seconds into the flight and the second doublet starts at 6.5 seconds. Both doublets are tracked by the FADS system as the aircraft is suddenly yawed back and forth. The later computations near landing also show the same sideslip of roughly $\beta=-3^{\circ}$ as the steady glide estimates.

\section{Conclusion}

A small, low-cost flush air data system intended for wind vector sensing in dynamic soaring UAVs is presented in this paper. The FADS system uses five pressure ports located on the nose of a small sailplane to 
replace large, damage-prone external vanes or probes. A hemispherical potential flow model is used to design the system, but the non-invertible nature of the problem requires a more complex solution. Single Hidden Layer neural networks are used to determine regression models for computing airspeed, angle of attack, and angle of sideslip. These networks are trained using input data collected during wind tunnel testing of the aircraft and FADS configuration. The results report an average error under $0.2 \mathrm{~m} / \mathrm{s}$ for airspeed, $0.6^{\circ}$ for $\alpha$, and $0.2^{\circ}$ for $\beta$ is possible with the system. The models are then applied to flight test data to observe the behavior of the FADS system in realistic conditions. The SHL-fitted models compute realistic wind vector parameters from the measured pressure data and are partially validated using GPS measurements. Further flight tests with more thorough validation techniques would greatly benefit the analysis. Even without a more complex analysis, the preliminary results of the simple nosecone FADS system confirm the viability of the method as a potential solution to the estimation problem for practical dynamic soaring.

\section{References}

${ }^{1}$ Allen, M. J. and Lin, V., "Guidance and Control of an Autonomous Soaring Vehicle with Flight Test Results," 45th AIAA Aerospace Sciences Meeting and Exhibit, No. AIAA Paper 2007-867, Reno, Nevada, January 2007.

${ }^{2}$ Andersson, K., "Extending Endurance for Small UAVs by Predicting and Searching for Thermal Updrafts," Mechanical and Astronautical Engineering Dept., Naval Postgraduate School, Monterey, California, 2009.

${ }^{3}$ Andersson, K., Kaminer, I., and Jones, K. D., "Autonomous Soaring; Flight Test Results of a Thermal Centering Controller," AIAA Guidance, Navigation, and Control Conference, No. AIAA Paper 2010-8034, Toronto, Ontario, Canada, August 2010.

${ }^{4}$ Edwards, D. J., "Implementation Details and Flight Test Results of an Autonomous Soaring Controller," AIAA Guidance, Navigation, and Control Conference, Reston, Virginia, 2008.

${ }^{5}$ Edwards, D. J. and Silverberg, L. M., "Autonomous Soaring: The Montague Cross-Country Challenge," Journal of Aircraft, Vol. 47, No. 5, September-October 2010, pp. 1763-1769.

${ }^{6}$ Rayleigh, "The Soaring of Birds," Nature, April 1883, pp. 534-535.

${ }^{7}$ Pennyquick, C. J., "Gust Soaring as a Basis for the Flight of Petrels and Albatrosses (Procellariiformes)," Avian Science, Vol. 2, No. 1, 2002.

${ }^{8}$ Gordon, R., Optimal Dynamic Soaring for Full Sized Sailplanes, Master's thesis, Air Force Institude of Technology, September 2006 .

${ }^{9}$ Sachs, G., Traugott, J., and Holzapfel, F., "Progress Against the Wind with Dynamic Soaring - Results from In-Flight Measurements of Albatrosses," AIAA Guidance, Navigation, and Control Conference, No. AIAA Paper 2011-6225, Portland, Oregon, August 2011.

${ }^{10}$ Barnes, J. P., "How Flies the Albatross: The Flight Mechanics of Dynamic Soaring," Online Presentation, May 2011.

${ }^{11}$ Space Age Control, "State-of-the-Art Air Data Products Solutions Guide," Online, June 2012.

${ }^{12}$ Larson, T. and Siemers, P. M., "Use of Nose Cap and Fuselage Pressure Orifices for Determination of Air Data for Space Shuttle Orbiter Below Supersonic Speeds," Tech. Rep. 1643, National Aeronautics and Space Administration, September 1980.

${ }^{13}$ Whitmore, S. A., Cobleigh, B. R., and Haering, E. A., "Design and Calibration of the X-33 Flush Airdata Sensing (FADS) System," Tech. Rep. 206540, National Aeronautics and Space Administration, Dryden Flight Research Center, January 1998.

${ }^{14}$ Larson, T., Whitmore, S. A., Ehernberger, L. J., Johnson, J. B., and Siemers, P. M., "Qualitative Evaluation of a Flush Air Data System at Transonic Speeds and High Angles of Attack," Tech. Rep. 2716, National Aeronautics and Space Administration, April 1987.

${ }^{15}$ Larson, T. J. and Siemers, P. M., "Subsonic Tests of an All-Flush-Pressure-Orifice Air Data System," Tech. Rep. 1871, National Aeronautics and Space Administration, June 1981.

${ }^{16}$ Crowther, W. J. and Lamont, P. J., "A Neural Network Approach to the Calibration of a Flush Air Data System," School of Engineering, University of Manchester.

${ }^{17}$ Calia, A., Denti, E., Galatolo, R., and Schettini, F., "Air Data Compution Using Neural Networks," Journal of Aircraft, Vol. 45, No. 6, November-December 2008, pp. 2078-2083.

${ }^{18}$ Rohloff, T. J., Whitmore, S. A., and Catton, I., "Air Data Sensing from Surface Pressure Measurements Using a Neural Network Method," AIAA Journal, Vol. 36, No. 11, November 1998, pp. 2094-2101.

${ }^{19}$ Samy, I., Postlethwaite, I., , and Gu, D.-W., "Neural-Network-Based Flush Air Data Sensing System Demonstrated on a Mini Air Vehicle," Journal of Aircraft, Vol. 47, No. 1, January-February 2010, pp. 18-31.

${ }^{20}$ Paces, P., Draxler, K., Hanzal, V., Censky, T., and Vasko, O., "A Combined Angle of Attack and Angle of Sideslip Smart Probe with Twin Differential Sensor Modules and Doubled Output Signal," IEEE Sensors 2010 Conference, Institute of Electrical and Electronics Engineers, 2010.

${ }^{21}$ Chen, X. Q., Ou, Q., Wong, D. R., Li, Y. J., Sinclair, M., and Marburg, A., "Flight Dynamics Modelling and Experimental Validation for Unmanned Aerial Vehicles," Mobile Robots - State of the Art in Land, Sea, Air, and Collaborative Missions, edited by X. Q. Chen, Y. Q. Chen, and J. G. Chase, chap. 9, InTech, 2009, pp. $177-202$.

${ }^{22}$ Parameswaran, V., Jategaonkar, R. V., and Press, M., "Five-Hole Flow Angle Probe Calibration from Dynamic and Tower Flyby Maneuvers," Journal of Aircraft, Vol. 42, No. 1, 2005, pp. 80-86.

${ }^{23}$ Wenger, C. W. and Devenport, W. J., "Seven-Hole Pressure Probe Calibration Method Utilizing Look-Up Error Tables," AIAA Journal, Vol. 37, No. 6, 1999, pp. 675-679.

${ }^{24}$ MathWorks, Inc., "Neural Network Toolbox," Online, June 2012. 

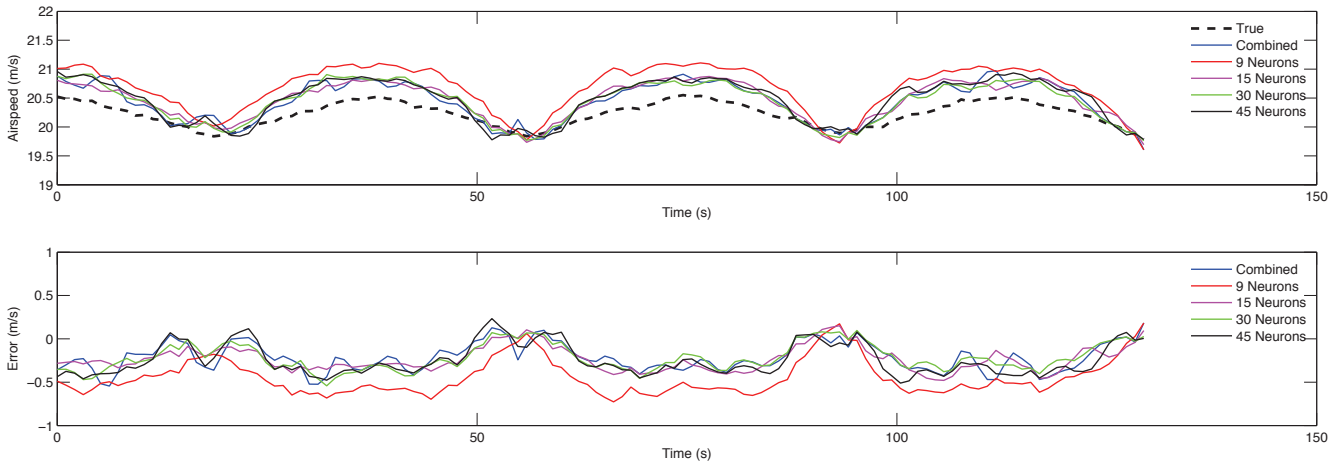

(a) Airspeed Performance
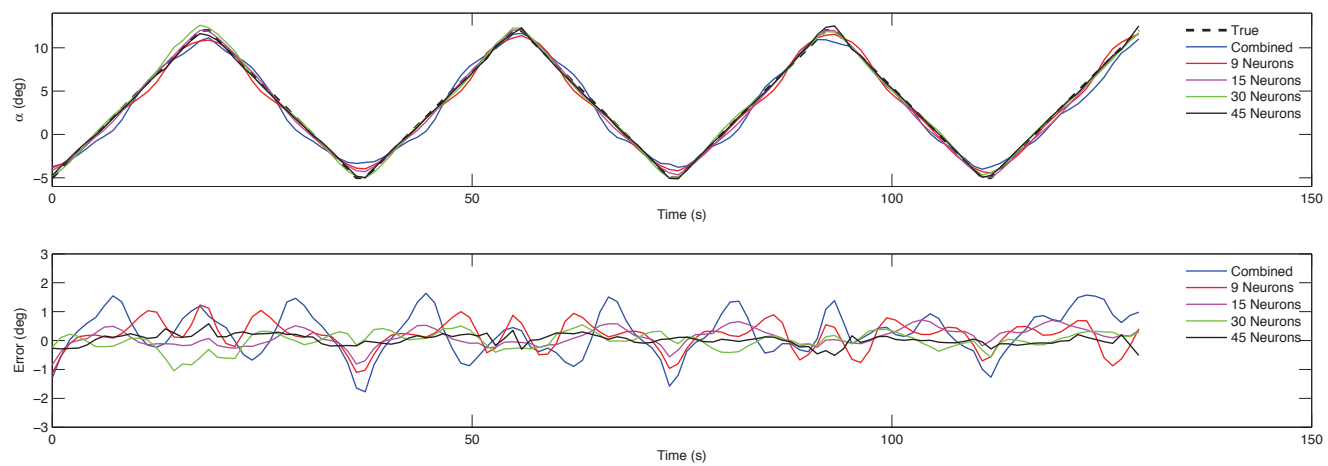

(b) Angle of Attack Performance
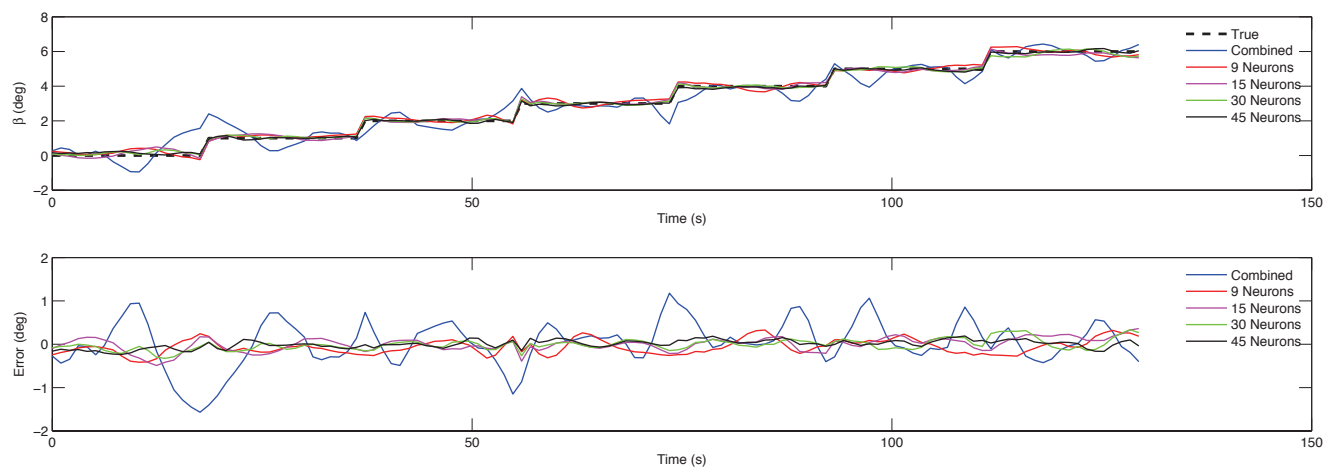

(c) Angle of Sideslip Performance

Figure 10. Performance of the models at nominally $20 \mathrm{~m} / \mathrm{s}$ with $-5^{\circ} \leq \alpha \leq 12^{\circ}$ and $0^{\circ} \leq \beta \leq 6^{\circ}$. 

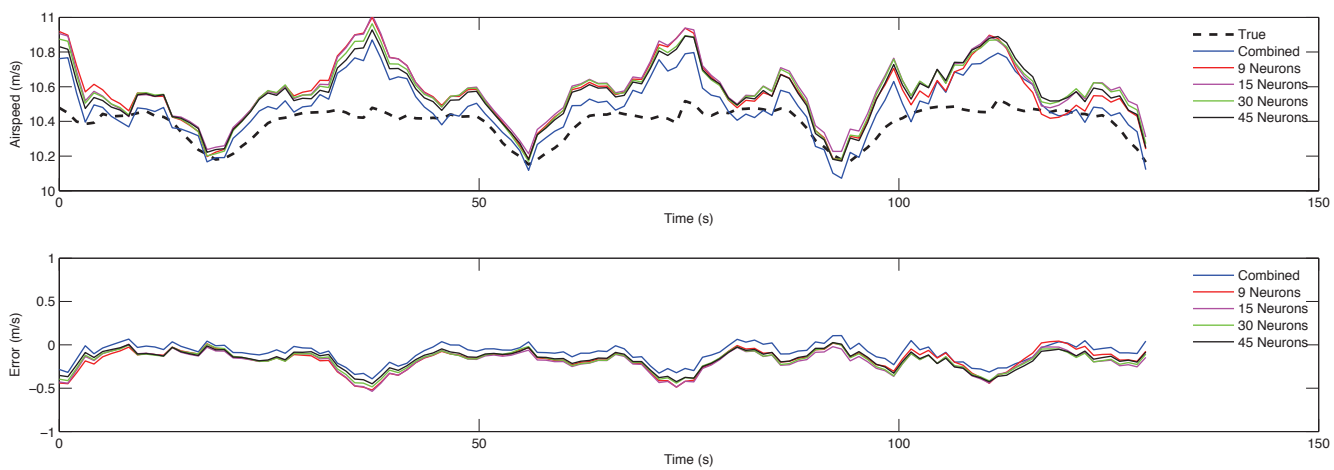

(a) Airspeed Performance
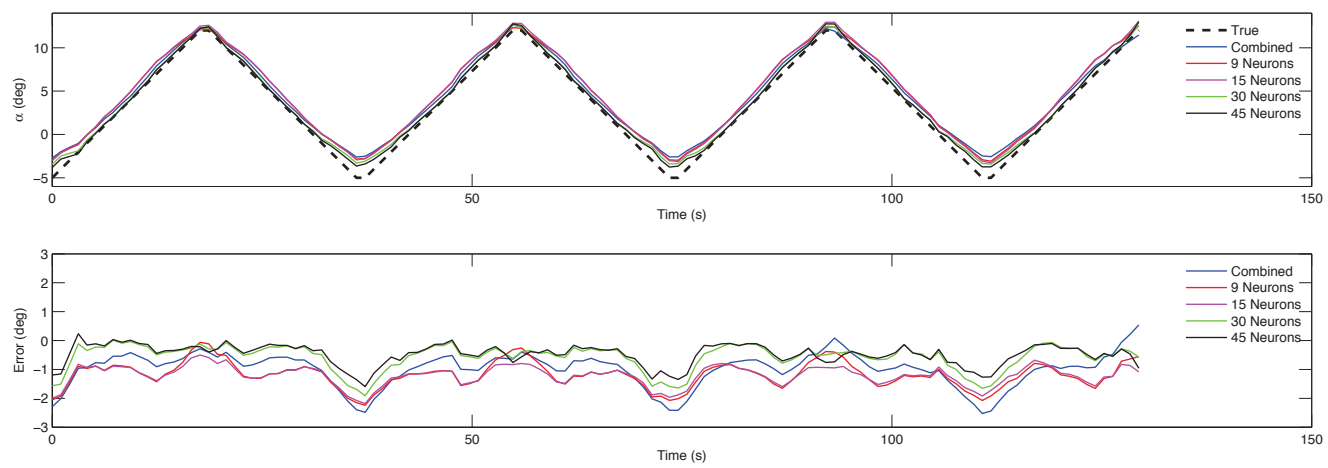

(b) Angle of Attack Performance
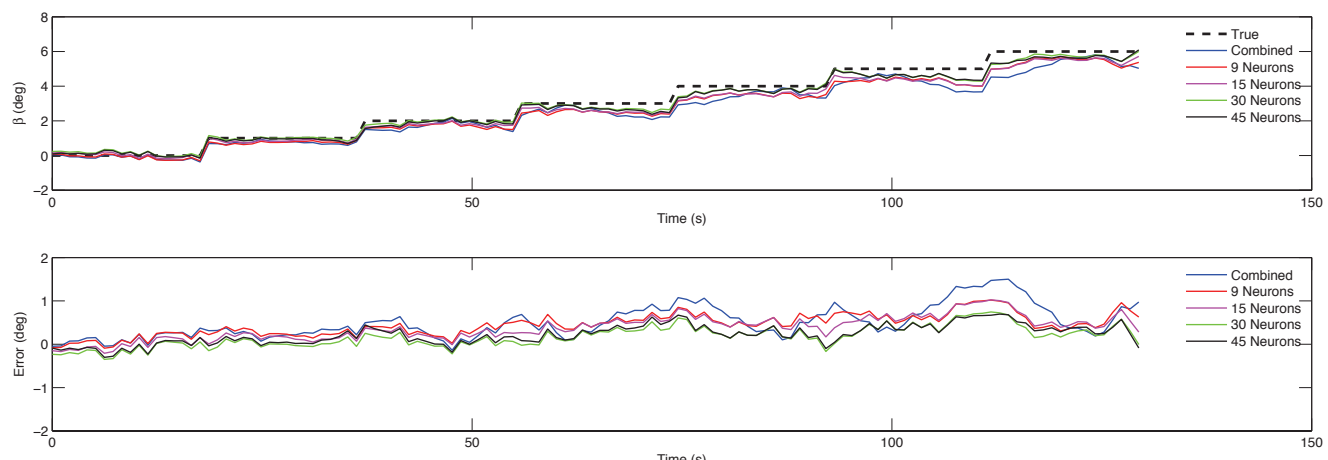

(c) Angle of Sideslip Performance

Figure 11. Performance of the models at nominally $10 \mathrm{~m} / \mathrm{s}$ with $-5^{\circ} \leq \alpha \leq 12^{\circ}$ and $0^{\circ} \leq \beta \leq 6^{\circ}$. 


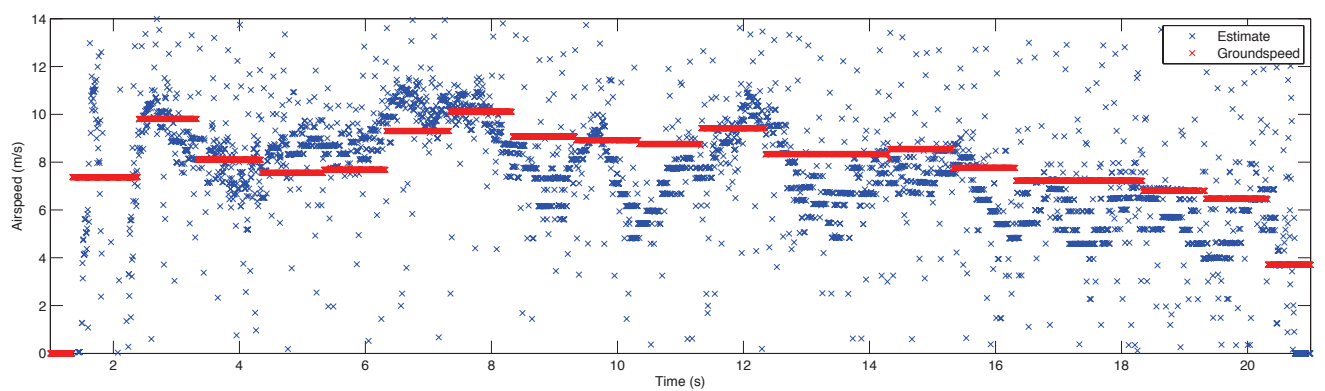

(a) Airspeed

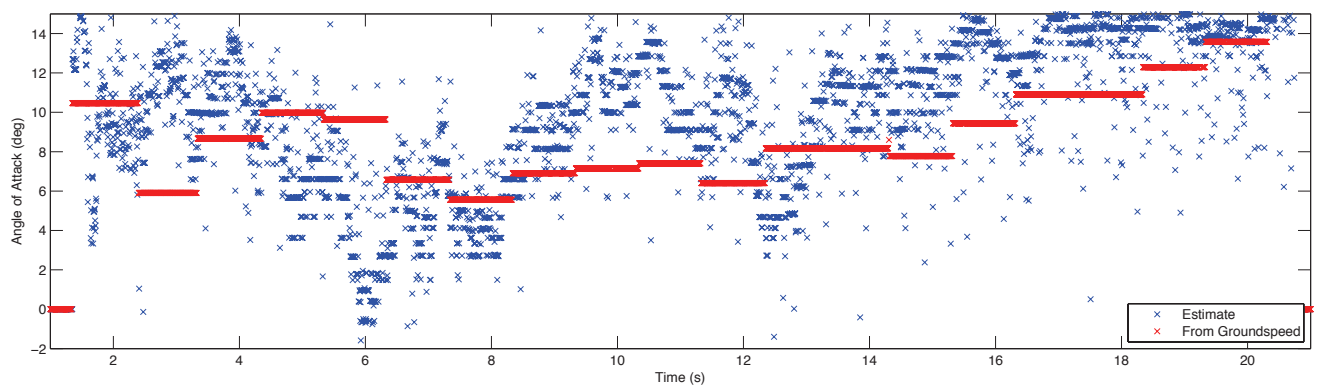

(b) Angle of Attack

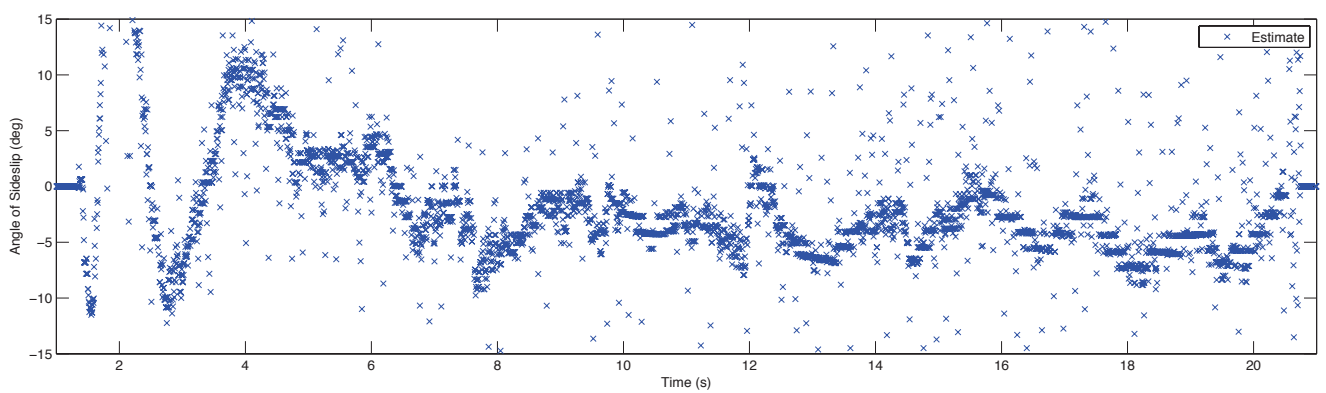

(c) Angle of Sideslip

Figure 12. Wind vector computations for a steady glide.

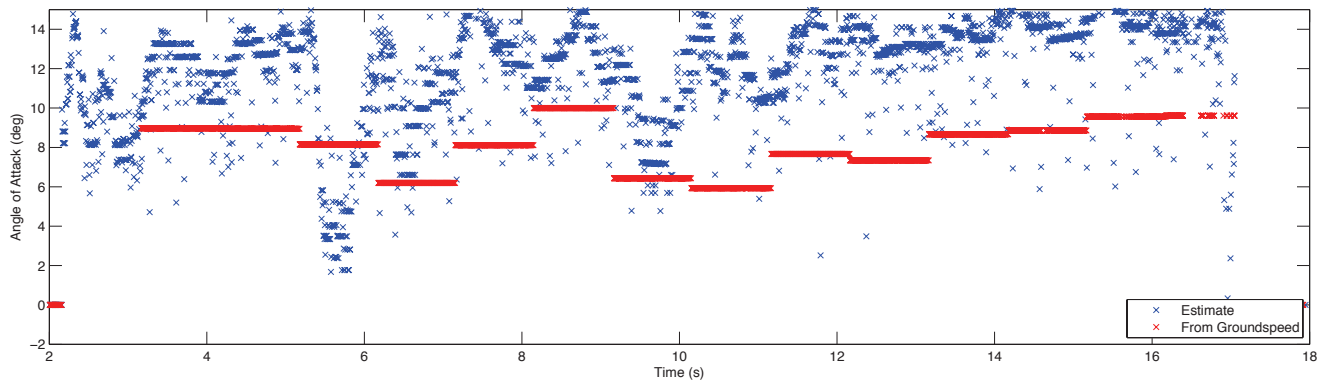

Figure 13. Angle of attack computation for two elevator doublets. The first down began at 5.5 seconds with a nose down elevator deflection while the second down elevator command began at 9.5 seconds. 


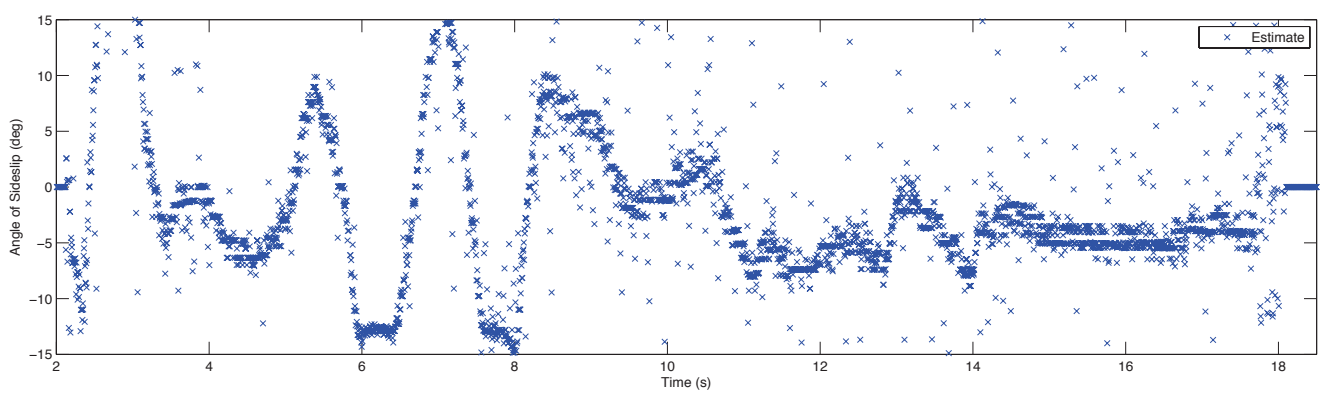

Figure 14. Angle of sideslip computation for two rudder doublets. The first doublet began at 5 seconds with a left rudder command while the second began at seconds with another left rudder deflection. 